\title{
Nature of the underlying heart disease affects survival in pediatric patients undergoing extracorporeal cardiopulmonary resuscitation
}

\author{
Joseph Philip, MD, ${ }^{a}$ Cole Burgman, CCP, ${ }^{\text {,e }}$ Aarti Bavare, MD, MPH, ${ }^{c, e}$ Ayse Akcan-Arikan, MD, ${ }^{c, e}$ \\ Jack F. Price, MD, ${ }^{\mathrm{c}, \mathrm{d}, \mathrm{e}}$ Iki Adachi, MD, ${ }^{\mathrm{e}, \mathrm{f}}$ and Lara S. Shekerdemian, MD, MHA ${ }^{\mathrm{e}, \mathrm{g}}$
}

Objective: To describe the use of extracorporeal membrane oxygenation (ECMO) in acute resuscitation after cardiac arrest in pediatric patients with heart disease, with reference to patient selection and predictors of outcome.

\begin{abstract}
Methods: A retrospective medical record review was performed of all patients aged $\leq 21$ years with heart disease who had undergone ECMO for cardiopulmonary resuscitation (ECPR) at Texas Children's Hospital from January 2005 to December 2012. The most recent Pediatric Overall Performance Category score was determined from the patients' medical records.
\end{abstract}
Results: During the study period, 62 episodes of ECPR occurred in 59 patients, with 27 (46\%) surviving to hospital discharge and $25(43 \%)$ alive at the most recent follow-up visit. The overall survival to discharge for patients with myocardial failure (myocarditis, cardiomyopathy, or after transplantation) and structural heart disease was similar $(40 \%$ vs $50 \%, P=.6)$. No patient with restrictive cardiomyopathy survived; 1 patient $(13 \%)$ in ECPR group after late cardiac graft failure survived to discharge. Survival to discharge was greater for patients who were intubated $(70 \%)$ at cardiac arrest $(P=.001)$. The presence of pre-existing acute kidney injury at cardiac arrest $(62 \%)$ was associated with greater mortality $(P=.059)$. A Pediatric Overall Performance Category score of $\leq 2$ (indicating good neurologic performance) was present in $68 \%$ of the survivors; 7 patients $(87 \%)$ with a score $>2$ had abnormal imaging findings $(P=.01)$.

Conclusions: ECPR was associated with modest survival in pediatric patients with heart disease; however, this was associated in part with the underlying disease and pre-existing comorbidities, including the presence of acute kidney injury. (J Thorac Cardiovasc Surg 2014;148:2367-72)

Extracorporeal membrane oxygenation (ECMO) in the setting of active cardiopulmonary resuscitation (ECPR) has gained widespread acceptance in the resuscitation algorithm for pediatric patients with heart disease. ${ }^{1}$ ECMO itself is a highly specialized, low-volume therapy that has been associated with significant morbidity and mortality and consumes substantial resources. It has generally been accepted that the subset of ECMO patients receiving ECPR represents the greatest risk subgroup in terms of mortality and long-term morbidity. The Extracorporeal Life

\footnotetext{
From the Congenital Heart Center, ${ }^{\text {a }}$ Shands Children's Hospital, University of Florida, Gainsville, Fla; Section of Critical Care and Congenital Heart Surgery, ${ }^{\text {b }}$ Section of Critical Care Medicine, ${ }^{\mathrm{c}}$ and Section of Cardiology, ${ }^{\mathrm{d}}$ Department of Pediatrics, ${ }^{\mathrm{e}}$ and Section of Congenital Heart Surgery, ${ }^{\mathrm{f}}$ Department of Surgery, Baylor College of Medicine, Houston, Tex; and Section of Critical Care, ${ }^{\mathrm{g}}$ Texas Children's Hospital, Houston, Tex.

Disclosures: Authors have nothing to disclose with regard to commercial support.

The work was performed in the Section of Critical Care Medicine, Section of Cardiology, and Section of Congenital Heart Surgery, Department of Pediatrics, Baylor College of Medicine and Texas Children's Hospital, Houston, Tex.

Received for publication Jan 4, 2014; revisions received Feb 24, 2014; accepted for publication March 13, 2014; available ahead of print April 27, 2014.

Address for reprints: Lara S. Shekerdemian, MD, MHA, Section of Critical Care,

Texas Children's Hospital, 6621 Fannin St, Houston, TX 77030 (E-mail: 1ssheker@texaschildrens.org).

$0022-5223 / \$ 36.00$

Copyright (c) 2014 by The American Association for Thoracic Surgery

http://dx.doi.org/10.1016/j.jtcvs.2014.03.023
}

Support Organization has reported the survival to hospital discharge after ECPR in patients aged $<18$ years at around $40 \%$, and, in many centers, ECPR now constitutes about one half of all cardiac ECMO support. ${ }^{2}$

As the use of ECPR has continued to grow, it has come under increasing scrutiny with respect to cost, indications, patient selection, and patient outcomes. Lowry and colleagues ${ }^{3}$ recently showed that the hospital charges incurred after ECPR were more than twice that of the propensitymatched conventional CPR, with no overall difference in survival from a multi-institutional outcomes database. The indications for ECPR are broad, with the most prominent subgroups being children with structural heart disease (SHD) and those with myocardial failure (eg, myocarditis, cardiomyopathy, or failure of the transplanted heart). When considering the outcomes after therapy as invasive as ECPR, one must consider factors other than survival to discharge from the ECMO center, the primary endpoint for the Extracorporeal Life Support Organization registry. Longer term survival and the associated burden of disease, in particular, neurodisability, are important outcome measures in this high-risk population. It is likely that patient selection will be vitally important in making good use of this resource.

The purpose of the present study was to retrospectively review our institutional experience with ECPR in pediatric patients with heart disease in a mixed medical and surgical 


$$
\begin{aligned}
\text { Abbreviations and Acronyms } \\
\text { AKI }=\text { acute kidney injury } \\
\text { CVICU = cardiovascular intensive care unit } \\
\text { ECMO = extracorporeal membrane oxygenation } \\
\text { ECPR = extracorporeal cardiopulmonary } \\
\text { resuscitation } \\
\text { IQR = interquartile range } \\
\text { POPC = Pediatric Overall Performance Category } \\
\text { RIFLE = risk, injury, failure, loss, and end-stage } \\
\text { renal function } \\
\text { SHD = structural heart disease } \\
\text { TCAD = transplant-related coronary artery disease }
\end{aligned}
$$

cardiovascular intensive care unit (CVICU). Our emphasis was on the outcomes in terms of survival to discharge and neurologic status at follow-up and on the patient factors that might influence these outcomes.

\section{METHODS}

The institutional review board of Baylor College of Medicine approved the present study. We identified all CVICU patients at Texas Children's Hospital who had required ECPR from April 2005 to December 2012. The start point of our review was selected because it marked the formal introduction of an ECPR protocol in the CVICU, with the availability of a plasmalyte-primed ECMO circuit at all times. ECPR was defined as the initiation of ECMO support in the setting of active CPR. The present review included patients who had had cardiac arrest outside the CVICU (the inpatient floor, emergency department, catheterization laboratory) who had undergone cannulation for ECMO and had received ongoing care in the CVICU. The decision to initiate ECMO was made by the cardiac surgeon, cardiac intensivist, and cardiologist, where possible, with the family's written or verbal consent to proceed.

\section{Patients}

All patients through the age of 21 years (pediatric age group as defined by the American Academy of Pediatrics) with SHD or myocardial failure who had received ECPR were included in the present review. We collected demographic profiles for all the patients, the details of the underlying disease, the clinical parameters immediately before cardiac arrest, including patient location, the use of mechanical ventilation, the use of inotropes, renal function, and laboratory values, including lactate and $\mathrm{pH}$. We used the pediatric risk, injury, failure, loss, and end-stage renal function (RIFLE) score to classify acute kidney injury (AKI) in patients according to the last creatinine clearance measurement before cardiac arrest. ${ }^{4}$ The duration of the cardiac arrest before establishing ECMO, the cannulation site, ECMO duration, surgical procedures during support, major complications, organ system failure, hospital stay length, and patient survival to discharge were also recorded. For nonsurvivors, we documented the timing and cause of death (including later mortality after initial hospital discharge).

\section{Neurologic Assessment}

For survivors, we recorded the results of the neurologic assessment at the most recent follow-up point using the Pediatric Overall Performance Category (POPC) score. ${ }^{5-7}$ The POPC score assesses cognitive impairment and functional morbidity, including general adaptive or physical limitations after critical illness or injury. It has a 6-point graded scale from normal function (score, 1) to death (score, 6). A POPC score of $\leq 2$ indicates a good neurologic outcome consistent with mild disability at most. A score $>2$ indicates a poor neurologic outcome, consistent with moderate to severe disability. ${ }^{5,8}$ The source and point of assessment was the documentation in our electronic medical records from the most recent office visit with the pediatrician, cardiologist, occupational therapist, or neurologist.

\section{ECMO Support}

Our in-house ECPR equipment throughout the period of review included a centrifugal ECMO pump and a wet-primed circuit that was available at all times. In the early part of our experience, we used a Biomedicus pump (Medtronic, Minneapolis, Minn) and Minimax oxygenator (Medtronic). Since 2009, we have been using the HL20 console with the Rotaflow pump (Maquet, Hirrlingen, Germany) and the pediatric or adult Quadrox hollow-fiber oxygenator (Maquet). After the establishment of ECMO, where possible, catecholamine medications were weaned, followed by the initiation of vasodilators. Mechanical ventilation was initially reduced to the "rest settings," with total ventilatory pressures of 20/10, a mandatory rate of 10 breaths $/ \mathrm{min}$, and an inspired oxygen fraction of $<0.4$. A heparin infusion was begun at 10 to $20 \mathrm{U} / \mathrm{kg} / \mathrm{h}$ and adjusted to maintain an activated clotting time of 180 to $200 \mathrm{~s}$, heparin (anti-Xa) level of 0.4 to 0.7 , and an antithrombin level $>80 \%$. Muscle relaxants were not routinely used after stabilization on ECMO and regular sedation weaning was performed to provide an opportunity to assess the neurologic status. In younger infants, cranial ultrasound examinations were performed every 24 to 48 hours. Also, although we did not have a specific protocol relating to computed tomography or the use of electroencephalography, these were frequently performed to assist with the overall evaluation for brain injury. The application of hypothermia for 24 to 48 hours after arrest was not routine and was largely dependent on the treating clinician. Latterly, this adjunctive therapy was used very infrequently. However, ECMO was otherwise used to control the patient's body temperature at normothermia $\left(36.5^{\circ} \mathrm{C}-37^{\circ} \mathrm{C}\right)$. Renal replacement therapy (ultrafiltration or continuous hemofiltration) was performed routinely in most patients for initial and early fluid removal or to provide additional renal support in the presence of more established AKI or renal failure.

\section{Statistical Analysis}

Continuous data are presented as the median values with the interquartile range (IQR). The categorical data are expressed as the frequencies and percentages. The data variables were compared between the survivors and nonsurvivors. The continuous variables were compared using the MannWhitney rank sum test. All dichotomous variables were assessed using the Fisher exact test. Multivariate logistic regression analysis was used to identify the factors independently associated with survival after ECPR. All variables with a univariate regression level of significance of $P<.1$ were subsequently tested in a multivariable logistic regression model.

\section{RESULTS \\ Patient Characteristics}

During the period of review, 103 episodes of temporary ECLS occurred in 99 patients, of which $62(60.2 \%)$ were ECPR in 59 patients $(59.6 \%$; 3 patients underwent a second run of ECPR). The median age was 12.7 months (IQR, 1.2-91.5), and the median weight was $7.8 \mathrm{~kg}$ (IQR, 4-23). Of the 59 patients, $32(54 \%)$ had SHD and 27 had myocardial failure.

Of the 32 patients with SHD, 30 had undergone surgery: $20(66 \%)$ were within 30 days of surgery and $10(33 \%)$ were in the convalescent phase ( $>30$ days after surgery). The timing of ECPR in the group within 30 days of surgery 
TABLE 1. Patient characteristics

\begin{tabular}{|c|c|c|c|c|}
\hline Variable & All patients $(n=59)$ & Survivors $(n=27)$ & Nonsurvivors $(\mathbf{n}=32)$ & $P$ value \\
\hline Median age (mo) & $12.69(1.2-91)$ & $6.4(1.3-84.7)$ & $15.7(1.2-92.9)$ & .52 \\
\hline Median weight (kg) & $7.8(4-22.7)$ & $6.8(4.5-23)$ & $9(3.2-26)$ & .95 \\
\hline Failure to thrive & $17(28)$ & $5(18.5)$ & $12(37.5)$ & .12 \\
\hline Chromosomal anomaly & $8(13.5)$ & $3(11)$ & $5(15.6)$ & .6 \\
\hline AKI (RIFLE-I, F) & $37(62)$ & $13(48)$ & $24(75)$ & .03 \\
\hline \multicolumn{5}{|l|}{ Primary diagnosis } \\
\hline SHD, single ventricle & $17(28)$ & $8(29)$ & $9(28)$ & .8 \\
\hline SHD, biventricular & $15(25)$ & $8(29)$ & $7(22)$ & .49 \\
\hline Dilated cardiomyopathy & $6(10)$ & $3(12)$ & $3(9)$ & .82 \\
\hline Restrictive cardiomyopathy & $4(6.7)$ & $0(0)$ & $4(12.5)$ & .05 \\
\hline Myocarditis & $7(11.8)$ & $6(22)$ & $1(3)$ & .02 \\
\hline Long QT syndrome & $2(3.3)$ & $1(3)$ & $1(3)$ & .9 \\
\hline Post-transplant & $8(13.5)$ & $1(3)$ & $7(22)$ & .04 \\
\hline Time of arrest (7 AM-7 PM) & $46(77)$ & $22(81)$ & $24(75)$ & .24 \\
\hline Interval from arrest to ECMO ( $>30 \mathrm{~min})$ & $40(67)$ & $14(52)$ & $26(76)$ & .01 \\
\hline Median duration of ECMO (h) & $76(39-104)$ & $72(41-115)$ & $81(31-103)$ & .5 \\
\hline Mechanical ventilation immediately before arrest & $32(54)$ & $21(77)$ & $11(34)$ & $<.01$ \\
\hline Inotropes, 1 or none at arrest & $18(30)$ & $10(37)$ & $8(25)$ & .3 \\
\hline Location of arrest (ICU) & $36(61)$ & $18(66)$ & $18(56)$ & .4 \\
\hline Location of cannulation (ICU) & $29(49)$ & $11(40)$ & $18(56)$ & .23 \\
\hline Site of cannulation (central) & $34(57)$ & $20(74)$ & $14(43)$ & .02 \\
\hline $\mathrm{pH}$ before arrest $(<7.2)$ & $18(30)$ & $11(40)$ & $7(21)$ & .2 \\
\hline Lactate before arrest $(>5)$ & $28(47)$ & $14(51)$ & $14(43)$ & .5 \\
\hline Operative interventions on ECMO & $20(33)$ & $11(40)$ & $9(28)$ & .3 \\
\hline
\end{tabular}

Data presented as median (interquartile range) or n (\%). $A K I$, Acute kidney injury; $R I F L E$, risk, injury, failure, loss, and end-stage renal function; $I$, injury; $F$, failure; $S H D$, structural heart disease; $E C M O$, extracorporeal membrane oxygenation; $I C U$, intensive care unit.

was 2.0 days (IQR, 1.75-9.0) after surgery. The specific patient diagnosis for the postoperative patients was hypoplastic left heart syndrome in 6, pulmonary atresia with an intact ventricular septum in 4, atrioventricular septal defect in 4, double outlet right ventricle in 3, Shone's complex and variants in 3, transposition of the great arteries in 2, pulmonary atresia with a ventricular septal defect in 2, congenitally corrected transposition of the great arteries in 2 , truncus arteriosus in 1, and tricuspid atresia in 1. The cause of cardiac arrest included ventricular dysfunction in 10 , pulmonary hypertension in 3 , acute arrhythmia in 3 , and shunt compromise in 3 . The exact cause of the cardiac arrest was unknown in 11 patients. Two patients had unoperated SHD: one with pulmonary atresia and an intact ventricular septum who had acute cardiac compromise in the catheterization laboratory, and an older child with a late diagnosis of a transitional atrioventricular septal defect and acute pulmonary hypertension.

A total of 27 patients with myocardial failure (cardiomyopathy, arrhythmia, or myocarditis) underwent ECPR during the study period (Table 1). Eight patients underwent ECPR after orthotopic heart transplantation; the underlying pathophysiology was transplant-related coronary artery disease (TCAD) in 5, acute rejection in 1, and late graft failure in 2 . In these patients, the median interval between transplantation and ECPR was 6.0 years (IQR, 3.7-7.0).
Three patients underwent 2 runs of ECPR. The first patient presented first at 13 years with dilated cardiomyopathy; after ECPR, he underwent transplantation and was discharged. Six years later, he experienced cardiac arrest secondary to TCAD and did not survive after ECPR owing to a severe neurologic injury. The second patient was a 6-month-old infant who had presented with dilated cardiomyopathy and required ECPR. One week after being weaned from ECMO, the patient underwent a second run of ECPR and was transitioned to a left ventricular assist device. The patient subsequently underwent transplantation and was doing well at the latest follow-up point. The third patient had had 2 runs of ECPR in the same admission for compromise from TCAD 8 years after heart transplantation. While awaiting a heart, he experienced a third event at which point it was not thought appropriate to offer ECMO.

\section{Hospital Outcomes}

In the ECPR group, 35 (59.3\%) survived to decannulation and $27(45.7 \%)$ survived to hospital discharge. A total of 24 patients did not survive weaning from ECMO because of multiorgan failure with or without cardiac recovery in 16 $(50 \%)$ and severe neurologic injury leading to a withdrawal of support in $8(25 \%) ; 8$ patients $(25 \%)$ were weaned from ECMO but died before discharge. The cause of death was persistent heart failure due to TCAD in 4 , restrictive 


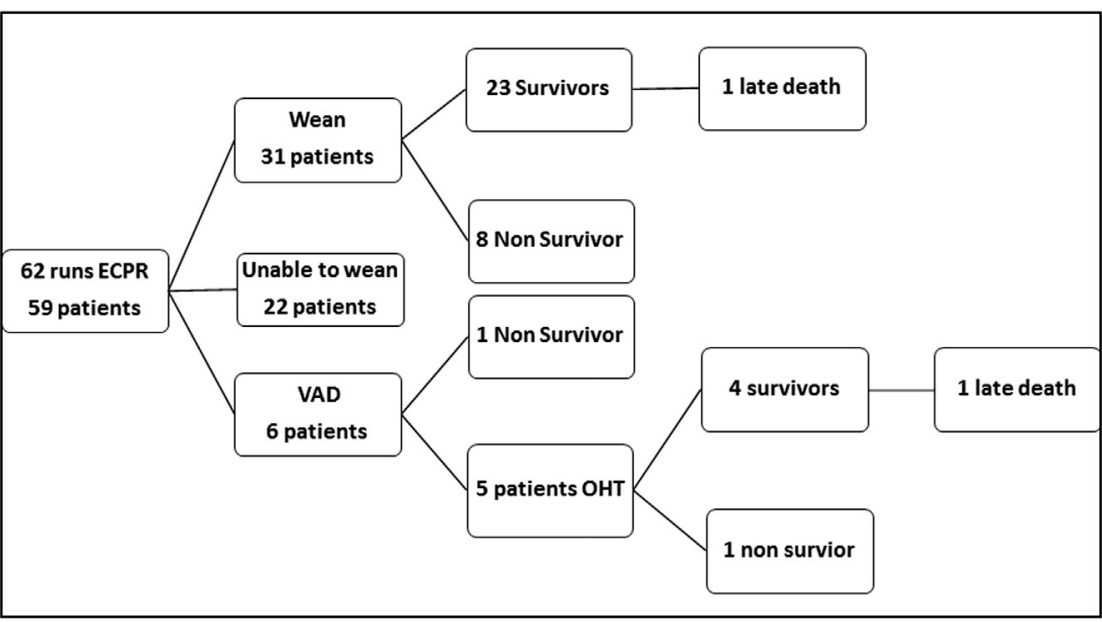

FIGURE 1. Outcomes for extracorporeal cardiopulmonary resuscitation in cardiac patients. $O H T$, Orthotopic heart transplantation; $V A D$, ventricular assist device; $E C P R$, extracorporeal cardiopulmonary resuscitation.

cardiomyopathy in 1, graft dysfunction in 1, shunt occlusion in 1 , and diffuse intravascular thrombosis in 1 . The median duration between decannulation and death was 49 days (IQR, 30-63).

Six patients were transitioned to a long-term ventricular assist device using complete cardiopulmonary bypass with the intention of bridging to heart transplantation (2 with primary dilated cardiomyopathy, 1 with TCAD, 1 with myocardial failure secondary to Kawasaki's disease, 1 with ventricular failure late after Fontan operation, and 1 with Shone's complex with muscular ventricular septal defects and pulmonary hypertension who had several failed attempts at closing the defects at outside institutions). Five patients underwent heart transplantation and were discharged home, of whom 3 were alive at the last follow-up point (Figure 1).

\section{Factors Affecting Hospital Survival}

In the patients with SHD, survival was similar in those with a functionally univentricular circulation and those with a biventricular circulation. A diagnosis of restrictive cardiomyopathy (no survivors) and ECPR late after cardiac transplantation were associated with nonsurvival. In contrast, a diagnosis of myocarditis, mechanical ventilation immediately before cardiac arrest, the absence of preexisting renal dysfunction (RIFLE failure or injury), a shorter CPR duration, and central cannulation were all associated with improved survival (Table 1). On multivariate analysis, improved hospital survival was associated with mechanical ventilation at cardiac arrest (OR, 8.5; 95\% CI, 2.48-35.6; $P=.0013$ ) and the absence of pre-existing AKI (OR, 3.5; 95\% CI, 0.975-14.6; $P=.059$ ).

\section{Outcomes at Follow-up}

The median follow-up period was 19 months (IQR, 8-59) from hospital discharge, at which point, 25 patients had survived ( $43 \%$ of the original cohort). Two deaths occurred after discharge: 1 in the patient with TCAD who had died after the second run of ECPR and the other secondary to an aspiration event 3 months after bidirectional Glenn. In terms of neurologic performance, 17 survivors $(68 \%)$ had a POPC score of $\leq 2$, indicating no neurologic injury or only mild injury. Of the 8 patients with a POPC score $>2,6(75 \%)$ had had a CPR duration of $>30$ minutes compared with $6(35 \%)$ with a POPC score of $\leq 2$ $(P=.06)$. The neurologic sequelae included global developmental delay in 3 patients ( 2 of whom were technology dependent at home), hemiparesis with speech delay in 1, seizures with mild delay in milestones in 3 , and documented learning deficit in 2 patients (although 1 patient had a POPC score of 2 with the learning disability). Twenty-three survivors had undergone brain imaging studies (ultrasonography in 1, computed tomography in 14 , and magnetic resonance imaging in 8), with abnormal results for $12(55 \%)$. A hypoxic injury was present in $5(22 \%)$, infarct with or without hemorrhage in $5(22 \%)$, isolated microcephaly in $1(4 \%)$, and isolated hemorrhage in $1(4 \%)$. Of the patients with a POPC score $>2,7(87 \%)$ had abnormal imaging results $(P=.01$; Table 2$)$.

\section{DISCUSSION}

In the present review, we have shown survival to hospital discharge after ECPR in a mixed population of children

TABLE 2. Neurologic status at follow-up for ECPR survivors

\begin{tabular}{lccc}
\hline \multicolumn{1}{c}{ Variable } & $\begin{array}{c}\text { POPC } \leq \mathbf{2} \\
(\mathbf{n}=\mathbf{1 7})\end{array}$ & $\begin{array}{c}\text { POPC }>\mathbf{2} \\
(\mathbf{n}=\mathbf{8})\end{array}$ & $\boldsymbol{P}$ value \\
\hline $\begin{array}{l}\text { Interval from arrest to ECMO } \\
(>30 \text { min) }\end{array}$ & $6(35)$ & $6(75)$ & .06 \\
Abnormal imaging findings & $5(29)$ & $7(87)$ & .01 \\
\hline $\begin{array}{l}\text { Data presented as n (\%). POPC, Pediatric Overall Performance Category; ECMO, } \\
\text { extracorporeal membrane oxygenation. }\end{array}$
\end{tabular}


with medical and surgical heart disease of $46 \%$, with subsequent survival to the most recent follow-up point of $43 \%$. We have also demonstrated significant variability in survival according to the nature of the underlying heart disease, with ECPR in the setting of restrictive cardiomyopathy or cardiac graft failure associated with very poor outcomes. We have shown for the first time that preexisting renal dysfunction according to the pediatric RIFLE classification is associated with mortality.

The overall survival to hospital discharge was similar to the published data relating to ECPR and to cardiac ECMO in general. ${ }^{9} 10$ In the present cohort, a diagnosis of SHD (single ventricle or biventricular physiology), myocarditis, and dilated cardiomyopathy were associated with the most favorable long-term outcomes. However, the presence of TCAD, graft failure, or restrictive cardiomyopathy was not. The published data have suggested that the overall outcomes for patients with TCAD while awaiting transplantation have been poor, with $50 \%$ of patients experiencing graft loss or death within 2 years of the diagnosis. ${ }^{11}$ Moreover, the risk of a poor outcome secondary to cardiac compromise or severe systemic infection after left ventricular assist device implantation as a bridge to repeat transplantation in this population is known to be very high, ${ }^{12}$ limiting the exit strategy for these patients. We had no survivors to discharge in the patients with restrictive cardiomyopathy. This diagnosis is known to be associated with an overall mortality rate of $50 \%$ within 2 years of the diagnosis, ${ }^{13,14}$ with an increased incidence of sudden cardiac death $^{15}$ and relatively high mortality during mechanical circulatory support compared with that of other subgroups. ${ }^{16}$ The complex circulatory physiology in this group could lead to inadequate systemic and myocardial oxygen delivery during CPR in these patients, contributing to the overall poor outcomes.

Survival after ECPR can be influenced by pre-existing patient factors at cardiac arrest. ${ }^{17}$ Although AKI at cardiac arrest has been associated with poor outcomes after ECMO, ${ }^{18}$ we have, for the first time, applied the pediatric RIFLE score to this population. We found a trend toward clinical significance in our patients, with increased survival in the group with no injury and risk, as determined by the RIFLE categories. These more subtle indicators of early or preclinical AKI might reflect a more prolonged state of impaired cardiac output that, when superimposed with an acute loss of cardiac output, reduces the chances of organ system recovery. Another precardiac arrest factor that conferred a significant protective effect on patient survival was already being intubated at the cardiac arrest. This is likely to be associated with a number of favorable factors, including the ability to provide full CPR without delay, the immediate presence of experienced ICU personnel, secure vascular access, and cardiovascular monitoring, with all immediately available at cardiac arrest. The duration of CPR before the initiation of ECLS has been a point of contention. ${ }^{17,19-21}$ Although our data did demonstrate a difference on univariate analysis, no difference was found after multivariate regression, likely reflection of our small sample size.

The overall outcomes of high-risk interventions should no longer simply be defined according to survival but should ideally include indicators of the quality of survival and long-term morbidity and burden. Although we did not have access to detailed neurodevelopmental or neurologic assessments of our patients, we did apply a widely used score (the POPC) to our cohort; $68 \%$ of our survivors had minimal or no neurologic disability at the last follow-up visit. This was comparable to the findings for other large cohorts, with severe neurologic disability varying from $9 \%$ to $40 \% .^{7,17,21-25}$ Six patients $(75 \%)$ with a POPC score $>2$ had had a CPR duration of $>30$ minutes, which was associated with a trend between the duration of CPR and the neurologic outcomes. Nine of our survivors had a significant neurologic impairment, varying from technology dependence (tracheostomy and gastrostomy tube) to a learning disability. Also, $87 \%$ of our patients with moderate to severe disability had abnormal neuroimaging findings. This indicates that neuroimaging in the setting of a formalized neurodevelopment assessment can be included as an integral part of long-term care.

The present study had several limitations. First, the retrospective nature of the study precluded the development of any predictive data points. These results were from a single-center experience and a heterogeneous population, limiting the generalizability of these results and the predictive power. Finally, the neurologic assessment for our survivors was determined by a review of the medical records from their last office visits rather than formal evaluations We did not have a baseline POPC score at discharge or before ECPR to make a comparison. We recognize these crucial limitations and are currently in the process of incorporating formal neurodevelopmental assessments for all our ECLS patients.

\section{CONCLUSIONS}

ECMO can be used as an adjunctive tool in resuscitation after cardiac arrest in children with heart disease. Important patient factors, including diagnostic group and the presence of pre-existing AKI, were identified as potential predictors for outcome after ECPR. These factors can be used not only to guide patient selection for ECPR, but also ideally to guide preemptive decision making regarding the institution of mechanical support.

We would like to thank Miss Bonnie Hendricks in helping with the collection of data and Dr Mohammed Khan in the sharing of data collection and technical assistance throughout this project. 


\section{References}

1. Kleinman ME, Chameides L, Schexnayder SM, Samson RA, Hazinski MF, Atkins DL, et al. Part 14: Pediatric advanced life support: 2010 American Heart Association guidelines for cardiopulmonary resuscitation and emergency cardiovascular care. Circulation. 2010;122(18 Suppl 3):S876-908.

2. Paden ML, Conrad SA, Rycus PT, Thiagarajan RR, ELSO Registry. Extracorporeal life support organization registry report 2012. ASAIO J. 2013;59:202-10.

3. Lowry AW, Morales DL, Graves DE, Knudson JD, Shamszad P, Mott AR, et al Characterization of extracorporeal membrane oxygenation for pediatric cardiac arrest in the United States: analysis of the Kids' Inpatient Database. Pediatr Cardiol. 2013;34:1422-30.

4. Akcan-Arikan A, Zappitelli M, Loftis LL, Washburn KK, Jefferson LS, Goldstein SL. Modified RIFLE criteria in critically ill children with acute kidney injury. Kidney Int. 2007;71:1028-35.

5. Fiser DH, Tilford JM, Roberson PK. Relationship of illness severity and length of stay to functional outcomes in the pediatric intensive care unit: a multiinstitutional study. Crit Care Med. 2000;28:1173-9.

6. Fiser DH, Long N, Roberson PK, Hefley G, Zolten K, Brodie-Fowler M. Relationship of pediatric overall performance category and pediatric cerebral performance category scores at pediatric intensive care unit discharge with outcome measures collected at hospital discharge and 1- and 6-month follow-up assessments. Crit Care Med. 2000;28:2616-20.

7. Chrysostomou C, Morell VO, Kuch BA, O’Malley E, Munoz R, Wearden PD Short- and intermediate-term survival after extracorporeal membrane oxygenation in children with cardiac disease. J Thorac Cardiovasc Surg. 2013;146: 317-25.

8. Fiser DH. Assessing the outcome of pediatric intensive care. J Pediatr. 1992;121: 68-74.

9. Brown KL, Ichord R, Marino BS, Thiagarajan RR. Outcomes following extracorporeal membrane oxygenation in children with cardiac disease. Pediatr Crit Care Med. 2013;14(5 Suppl 1):S73-83.

10. Sivarajan VB, Almodovar MC, Rodefeld MD, Laussen PC. Pediatric extracorporeal life support in specialized situations. Pediatr Crit Care Med. 2013; 14(5 Suppl 1):S51-61.

11. Kindel SJ, Pahl E. Current therapies for cardiac allograft vasculopathy in children. Congenit Heart Dis. 2012;7:324-35.

12. Cabrera AG, Khan MS, Morales DL, Chen DW, Moffett BS, Price JF, et al Infectious complications and outcomes in children supported with left ventricular assist devices. J Heart Lung Transplant. 2013;32:518-24.

13. Chen SC, Balfour IC, Jureidini S. Clinical spectrum of restrictive cardiomyopathy in children. J Heart Lung Transplant. 2001;20:90-2.
14. Kimberling MT, Balzer DT, Hirsch R, Mendeloff E, Huddleston CB, Canter CE. Cardiac transplantation for pediatric restrictive cardiomyopathy: presentation, evaluation, and short-term outcome. J Heart Lung Transplant. 2002;21:455-9.

15. Rivenes SM, Kearney DL, Smith EO, Towbin JA, Denfield SW. Sudden death and cardiovascular collapse in children with restrictive cardiomyopathy. Circulation. 2000;102:876-82.

16. Zangwill SD, Naftel D, L'Ecuyer T, Rosenthal D, Robinson B, Kirklin JK, et al. Outcomes of children with restrictive cardiomyopathy listed for heart transplant: a multi-institutional study. J Heart Lung Transplant. 2009;28:1335-40.

17. Kane DA, Thiagarajan RR, Wypij D, Scheurer MA, Fynn-Thompson F, Emani S, et al. Rapid-response extracorporeal membrane oxygenation to support cardiopulmonary resuscitation in children with cardiac disease. Circulation. 2010; 122(11 Suppl):S241-8.

18. Kelly RB, Harrison RE. Outcome predictors of pediatric extracorporeal cardiopulmonary resuscitation. Pediatr Cardiol. 2010;31:626-33.

19. Wolf MJ, Kanter KR, Kirshbom PM, Kogon BE, Wagoner SF. Extracorporeal cardiopulmonary resuscitation for pediatric cardiac patients. Ann Thorac Surg. 2012;94:874-9; discussion 879-80.

20. Huang SC, Wu ET, Wang CC, Chen YS, Chang CI, Chiu IS, et al. Eleven years of experience with extracorporeal cardiopulmonary resuscitation for paediatric patients with in-hospital cardiac arrest. Resuscitation. 2012;83:710-4.

21. Sivarajan VB, Best D, Brizard CP, Shekerdemian LS, d'Udekem Y, Butt W Duration of resuscitation prior to rescue extracorporeal membrane oxygenation impacts outcome in children with heart disease. Intensive Care Med. 2011;37: 853-60.

22. Prodhan P, Fiser RT, Dyamenahalli U, Gossett J, Imamura M, Jaquiss RD, et al. Outcomes after extracorporeal cardiopulmonary resuscitation (ECPR) following refractory pediatric cardiac arrest in the intensive care unit. Resuscitation. 2009; 80:1124-9.

23. Allan CK, Thiagarajan RR, Armsby LR, del Nido PJ, Laussen PC. Emergent use of extracorporeal membrane oxygenation during pediatric cardiac catheterization. Pediatr Crit Care Med. 2006;7:212-9.

24. Raymond TT, Cunnyngham CB, Thompson MT, Thomas JA, Dalton HJ, Nadkarni VM, et al. Outcomes among neonates, infants, and children after extracorporeal cardiopulmonary resuscitation for refractory inhospital pediatric cardiac arrest: a report from the National Registry of Cardiopulmonary Resuscitation. Pediatr Crit Care Med. 2010;11:362-71.

25. Alsoufi B, Al-Radi OO, Nazer RI, Gruenwald C, Foreman C, Williams WG, et al Survival outcomes after rescue extracorporeal cardiopulmonary resuscitation in pediatric patients with refractory cardiac arrest. J Thorac Cardiovasc Surg. 2007; 134:952-9.e2. 